\title{
Dual Versus Split Right Coronary Artery: What is there in the Name?
}

\author{
Surendra Kumar Naik, Raghav Bansal \\ Department of Cardiology, All India Institute of Medical Sciences, New Delhi, India \\ ORCID: \\ Surendra Kumar Naik: https://orcid.org/0000-0001-7507-3026 \\ Raghav Bansal: https://orcid.org/0000-0002-1649-8013
}

\section{Abstract}

Congenital coronary artery anomalies are rare which are generally detected incidentally during coronary angiograms. Double right coronary artery (RCA) is one such rare coronary anomaly, and various other terms are being used to describe it such as dual RCA or split RCA. However, no final consensus regarding definition of dual or split RCA has been made till now. We reported two different cases of double RCA and proposed to differentiate dual versus split RCA on the basis of their number of ostia from the right sinus of Valsalva. Various reports of increased atherosclerosis particularly in single ostial origin split RCA have been described recently. Their clinical implication lies in the fact that one should have background knowledge of such a rare coronary anomaly particularly during acute coronary syndromes with complete occlusion so that culprit artery could not be missed.

Keywords: Coronary artery anomaly, double right coronary artery, dual right coronary artery, split right coronary artery

\section{INTRODUCTION}

Coronary artery anomalies have been reported to be infrequent in the general population. Double right coronary artery (RCA) is a rare coronary anomaly with description limited to only a few case reports. No consensus definition is available and controversy over its nomenclature ensues. We hereby describe two cases with two parallel coronary arteries coursing through the right atrioventricular groove. We further try to differentiate between dual and split RCA based on a separate or a common origin from the right coronary sinus, respectively.

\section{Case Report}

\section{Case 1}

A 24-year-old male underwent coronary angiogram for the evaluation of dilated cardiomyopathy. Left coronary artery system was normal in origin and course. RCA injection revealed two arteries coursing through the right

Received: 25-05-2021 Revised: 18-06-2021 Accepted: 25-06-2021

Published Online: 25-09-2021

\begin{tabular}{|l|l|}
\hline \multicolumn{3}{|c|}{ Access this article online } \\
\hline Quick Response Code: & Website: \\
\hline
\end{tabular}

atrioventricular groove with each giving a posterior descending artery (PDA) at its termination. On close inspection, both arteries had a separate origin in the right coronary sinus with the catheter hooking one of them and the other one being filled from the reflux of contrast from the ostium of the first one [Figure 1].

\section{Case 2}

A 48-year-old male underwent coronary angiogram for chronic coronary syndrome. Left coronary artery injection revealed a normal origin and course with a tight $95 \%$ tubular stenosis in the mid left anterior descending artery. RCA injection revealed a proximal RCA splitting into two parallel coronary arteries traversing the right atrioventricular groove and each giving a PDA at its termination [Figure 2]. Both arteries had no angiographically visible atherosclerotic disease.

Address for correspondence: Dr. Raghav Bansal, Department of Cardiology, All India Institute of Medical Sciences, New Delhi - 110 029, India. E-mail: raghav.mamc@gmail.com

This is an open access journal, and articles are distributed under the terms of the Creative Commons Attribution-NonCommercial-ShareAlike 4.0 License, which allows others to remix, tweak, and build upon the work non-commercially, as long as appropriate credit is given and the new creations are licensed under the identical terms.

For reprints contact: WKHLRPMedknow_reprints@wolterskluwer.com

How to cite this article: Naik SK, Bansal R. Dual versus split right coronary artery: What is there in the name? Int J Cardiovasc Acad 2021;7:100-2. 


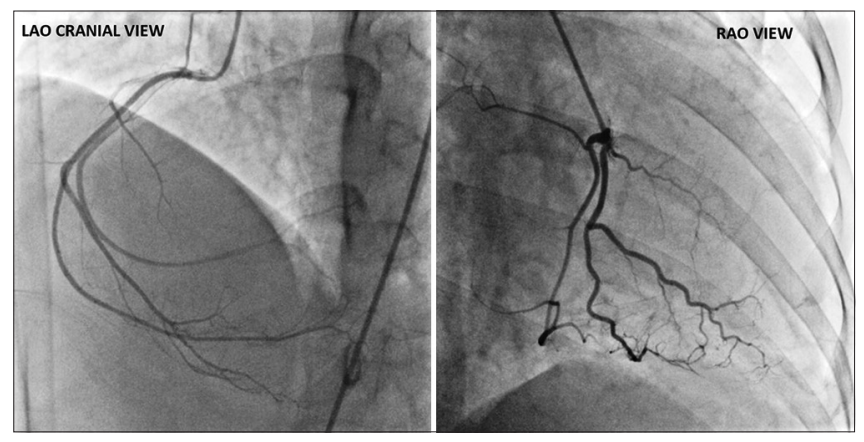

Figure 1: Coronary angiogram of right coronary artery in the left anterior oblique cranial view and right anterior oblique view demonstrating dual right coronary artery with a separate origin

\section{Discussion}

Coronary artery anomalies have been reported to be rare with an estimated prevalence of $0.2 \%-1.4 \%$ in the general population. ${ }^{[1]}$ Double RCA is one of the rarest of coronary anomalies with its description limited to a few case reports. In a study of 7400 coronary angiograms, Harikrishnan et al. found double RCA in only one patient with an incidence of $0.01 \% \cdot{ }^{[2]}$ In another study, double RCA was found in two out of 2957 patients $(0.07 \%$ incidence $) \cdot{ }^{[3]} \mathrm{A}$ double RCA has been defined as two arterial branches of similar size coursing together for at least half of the distance, in the right atrioventricular groove. ${ }^{[4]}$ The anomaly has been variably called as "dual RCA," "duplicated RCA," and "split RCA." Whether these are different names of the same anomaly or are different anomalies remain a controversial issue.$^{[5]}$ Lemburg et al. have suggested that true double RCA is defined only in the presence of separate ostial origin of RCA. ${ }^{[6]}$ On the contrary, Sawaya et al. have proposed that split and double RCA are names for the same coronary anomaly. ${ }^{[7]}$ Angelini et al. defined split RCA as a proximal PDA arising from distal RCA and distal PDA arising from acute marginal branch of mid RCA. ${ }^{[8]}$ As per this definition, split RCA was the most common coronary anomaly in their case series ( $1.23 \%$ in 1950 patients) ${ }^{[8]}$ Thus, the confusion over the nomenclature of this anomaly ensues.

The clinical importance lies in the recognition that both the branches need consideration for revascularization in case of ischemia. Our first case depicts two arteries in the right atrioventricular groove with separate origin from the right coronary sinus. In such a scenario, if only one of the arteries is opacified, the other blocked artery may be missed in an acute coronary syndrome. A high index of suspicion followed by a nonselective contrast injection in the right sinus may help to identify the anomaly. The second case describes two arteries arising from a common ostial origin and has been more commonly reported in the literature. For clear distinction between the two, we hereby propose that two RCAs with separate ostial origin should be called as a "dual RCA" and should be differentiated from the more commonly reported variant of common ostial origin which should be described as a "split RCA." Recently, increased atherosclerosis has

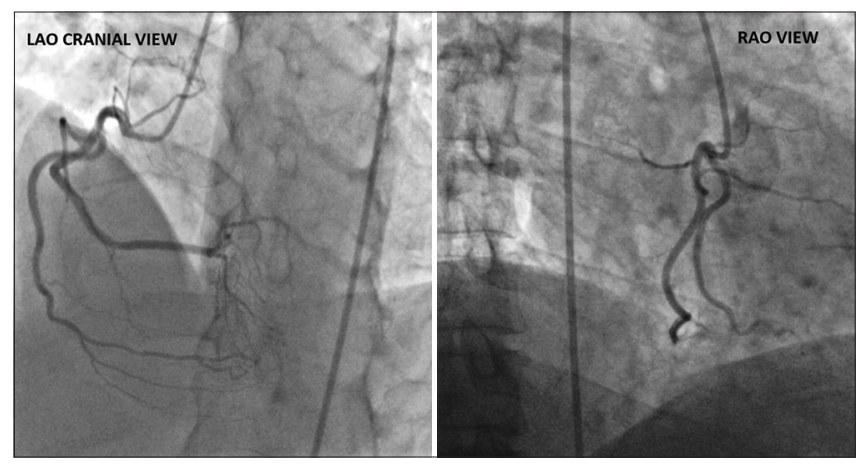

Figure 2: Coronary angiogram of right coronary artery in the left anterior oblique cranial view and right anterior oblique view demonstrating split right coronary artery with a common origin

been reported in double RCA anomalies, especially in those arising from common ostium probably because of altered blood flow kinetics at the branching point. ${ }^{[9]}$ The previous reports about the pathogenesis of atherosclerosis in double RCA suggested that only the atrioventricular branch of RCA is affected by atherosclerosis likely because of higher amount of fat in atrioventricular sulcus. ${ }^{[10]}$ However, the recent reports suggested that RCA originating from common ostium had much higher incidence of atherosclerosis as compared to RCA with separate ostium origin. A different mechanism for pathogenesis has been proposed. Since single ostium origin RCA has distal branching point and curve arterial segments, so low or oscillatory shear stress at this point causes increased atherosclerosis. While RCA with separate origins has no branching points and has straight arterial segments, so physiological shear stress appears to protect them from atherosclerosis. ${ }^{[9]}$ The possibility of missing a dual RCA is there if the catheter is deep hooked in one of the RCA with no or minimal reflux. One should be wary of not missing the anomaly while performing a coronary angiogram, especially in case of acute occlusion to prevent adverse patient outcome.

\section{Declaration of patient consent}

The authors certify that they have obtained all appropriate patient consent forms. In the form the patient(s) has/have given his/her/their consent for his/her/their images and other clinical information to be reported in the journal. The patients understand that their names and initials will not be published and due efforts will be made to conceal their identity, but anonymity cannot be guaranteed.

\section{Financial support and sponsorship \\ Nil.}

\section{Conflicts of interest}

There are no conflicts of interest.

\section{ReFERENCES}

1. Jacobs ML, Mavroudis C. Anomalies of the coronary arteries: Nomenclature and classification. Cardiol Young 2010;20 Suppl 3:15-9.

2. Harikrishnan S, Jacob SP, Tharakan J, Titus T, Kumar VK, Bhat A, 
et al. Congenital coronary anomalies of origin and distribution in adults: A coronary arteriographic study. Indian Heart J 2002;54:271-5.

3. Kunimasa $\mathrm{T}$, Sato $\mathrm{Y}$, Ichikawa $\mathrm{M}$, Ito $\mathrm{S}$, Takagi $\mathrm{T}$, Lee $\mathrm{T}$, et al. MDCT detection of double right coronary artery arising from a single ostium in the right sinus of Valsalva: Report of 2 cases. Int J Cardiol 2007;115:239-41.

4. Misuraca L, Balbarini A. Double right coronary artery or split right coronary artery: The same anomaly? J Cardiovasc Med (Hagerstown) 2010;11:398.

5. Chen Y, Chien T, Chen C, Lin C, Lee C. Double right coronary artery or split coronary artery? Int J Cardiol 2012;154:243-5.

6. Lemburg SP, Peters SA, Scheeler M, Nicolas V, Heyer CM. Detection of a double right coronary artery with 16-row multidetector computed tomography. Int J Cardiovasc Imaging 2007;23:293-7.

7. Sawaya FJ, Sawaya JI, Angelini P. Split right coronary artery: Its definition and its territory. Tex Heart Inst J 2008;35:477-9.

8. Angelini P, Villason S, Chan AV Jr., Diez JG. Normal and anomalous coronary arteries in humans. In: Angelini P, editor. Coronary Artery Anomalies: A Comprehensive Approach. Baltimore: Lippincott Williams and Wilkins; 1999. p. 27-79.

9. Chien TM, Chen CW, Chen HM, Lee CS, Lin CC, Chen YF. Double right coronary artery and its clinical implications. Cardiol Young 2014;24:5-12.

10. Angelini P. A rare coronary anomaly: Double right. Clin Cardio 2008;31:186. 